\title{
MATCHING, BARGAINING, AND WAGE SETTING IN AN EVOLUTIONARY MODEL OF LABOR MARKET AND OUTPUT DYNAMICS*
}

\author{
G. FAGIOLO \\ L.E.M., Sant'Anna School of Advanced Studies, Pisa, Italy \\ giorgio.fagiolo@sssup.it \\ G. DOSI \\ L.E.M., Sant'Anna School of Advanced Studies, Pisa, Italy \\ gdosi@sssup.it \\ R. GABRIELE \\ L.E.M., Sant'Anna School of Advanced Studies, Pisa, Italy \\ and \\ D.I.S.A., University of Trento, Trento, Italy \\ rgabriel@cs.unitn.it
}

In this paper, we present an agent-based, evolutionary, model of output- and labormarket dynamics. Firms produce a homogeneous, perishable, good under constant returns to scale using labor only. Labor productivities are firm-specific and change stochastically due to technical progress. The key feature of the model resides in an explicit microfoundation of the processes of: (i) matching between firms and workers; (ii) job search; (iii) wage setting; (iv) endogenous formation of aggregate demand; (v) endogenous price formation. Moreover, we allow for a competitive process entailing selection of firms on the basis of their revealed competitiveness. Simulations show that the model is able to robustly reproduce Beveridge, Wage and Okun curves under quite broad behavioral and institutional settings. The system generates endogenously an Okun coefficient greater than one even if individual firms employ production functions exhibiting constant returns to labor. Monte Carlo simulations also indicate that statistically detectable shifts in Okun and Beveridge curves emerge as the result of changes in institutional, behavioral, and technological parameters. Finally, the model generates sharp predictions about how system parameters affect aggregate performance (i.e. average GDP growth) and its volatility.

Keywords: Labor Markets, Dynamics, Aggregate Regularities, Beveridge Curve, Okun Curve, Wage Curve, Matching Models.

\footnotetext{
* Thanks to Uwe Cantner, Herbert Dawid, Peter Flaschel, Alan Kirman, Willi Semmler, Mauro Sylos Labini, Matteo Richiardi, Leigh Tesfatsion, two anonymous referees, and the participants to the conference "Wild@Ace: Workshop on Industry and Labor Dynamics. An Agent-based Computational Economics approach", Laboratorio Revelli, Turin, October 3-4, 2003, for valuable comments and suggestions.
} 


\section{Introduction}

In the last decades, the issue of microfoundations of macroeconomic dynamics has played a central role in the economic profession (cf. Dosi and Orsenigo (1994) for a discussion). Theoretical explanations of observed aggregate regularities have at least begun to employ formal frameworks where macroeconomic outcomes are interpreted as the result of the interactions of individual firms, workers, consumers, etc..

Traditionally, efforts of microfounding macroeconomic dynamics have been grounded upon a hyper-rational, maximizing, "representative agent", thus avoiding by construction the challenges posed by aggregation of heterogeneous agents (Kirman, 1992).

Despite their high formal sophistication, the degree of success of these models is, at best, mixed. In particular, they turn out to be unable to jointly account for multiple empirically observed "stylized facts". For example, as far as labor market dynamics is concerned, existing literature seems to completely lack a joint explanation of the most important aggregate regularities concerning: (i) the process through which firms and workers meet in the labor market; (ii) how this matching process affects wage setting and (un)employment dynamics; and (iii) the extent to which unemployment and output interact over the business cycle ${ }^{\mathrm{a}}$.

More specifically, existing (standard) microfoundations of labor market dynamics seem to have failed in jointly explaining three crucial stylized facts that one can typically observe in the data, namely: (a) the Beveridge curve, which predicts a negative relationship between rates of vacancies and rates of unemployment; (b) the Phillips (respectively, Wage) curve, suggesting that changes in wage rates (respectively, levels of wage rates) are negatively related to unemployment rates; (c) the Okun curve, which posits a more than proportional increase in real GDP for every one percentage point reduction in the unemployment rate.

In this paper, we propose an alternative, evolutionary-based, approach to the microfoundation of labor-market and output dynamics ${ }^{b}$. In the model we present in the following, the economy is populated by boundedly-rational firms and workers. Firms produce a homogeneous, perishable, good under constant returns to scale using labor as the sole input of production. Workers are skill-homogeneous and buy the good spending all their wage. Labor productivities are firm-specific and change stochastically due to technical progress. Both firms and workers hold expectations about desired wages they want to offer and get, and they are able to adaptively revise their expectations on the base of observed market dynamics.

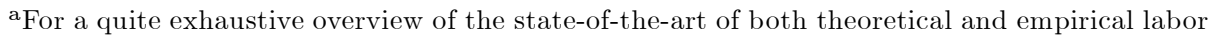
market literature, cf. Ashenfelter and Layard (1986), Ashenfelter and Card (1999) and Petrongolo and Pissarides (2001).

${ }^{\mathrm{b}}$ More on the general Weltanschauung of the evolutionary approach is in Dosi and Nelson (1994) and Dosi and Winter (2002). The model we present has large overlappings with the "AgentBased Computational Economics" (ACE) approach (Tesfatsion, 1997; Epstein and Axtell, 1996; Aoki, 2003), as well as with self-organization models of labor markets pioneered by Lesourne (1992). 
A key feature of the model resides in an explicit microfoundation of the processes of: (i) matching between firms and workers; (ii) job search; (iii) wage setting; (iv) endogenous formation of aggregate demand; (v) endogenous price formation. Moreover, in the spirit of evolutionary-based approaches, we allow for selection (e.g. exit) of firms on the basis of their revealed competitiveness (as measured by last-period profits). Since firms interact both in the labor market and in the product market, their revealed competitiveness is affected not only by their production decisions, but also by their hiring and wage-setting behaviors.

Macroeconomic dynamics is generated in the model via aggregation of individual behaviors. Statistical properties exhibited by aggregate variables might then be interpreted as emergent properties grounded on persistent micro disequilibria. Consequently, even when some equilibrium relationship exists between aggregate variables (e.g. inflows and outflows from unemployment), the economy might persistently depart from it and follow some disequilibrium path. The observed stable relations amongst those same aggregate variables might emerge out of turbulent, disequilibrium, microeconomic interactions.

Computer simulations show that the model is able to robustly and jointly reproduce Beveridge, Wage and Okun curves over sufficiently large regions of the parameter space. Moreover, the system endogenously generates (absolute values of) Okun coefficients larger than one even if production at the individual level does not enjoy increasing returns to labor. Monte Carlo simulations also indicate that statistically detectable shifts in Okun and Beveridge curves emerge as the result of changes in institutional, behavioral, and technological parameters. Finally, the model generates quite sharp predictions about how system parameters affect aggregate performance (i.e. average GDP growth) and its volatility.

Our results lend support to a disequilibrium foundation of aggregate regularities: despite the fact that the economy always departs from equilibrium (if any), aggregate regularities emerge as the outcome of decentralized interactions, adaptive behavioral adjustments, and imperfect coordination.

The paper is organized as follows. In Section 2 we briefly survey empirical findings about aggregate regularities in labor market dynamics and we discuss how mainstream economic theory has been trying to provide explanations of such stylized facts. In Section 3, we introduce the model. Sections 4 and 5 present the results of simulation exercises. Finally, in Section 6 we draw some concluding remarks.

\section{Labor Market Dynamics: Empirical Findings and Theoretical Explanations}

When dealing with the interplay between labor market and output dynamics, three aggregate stylized facts stand out.

First, the Beveridge curve (BC) postulates a negative relationship (over time) between the rate of unemployment $u$ and the rate of vacancies $v$, where rates are 
defined in terms of total employment ${ }^{c}$. The intuition is simple: if an economy experiments higher level of vacancies - in turn plausibly corresponding to a higher level of aggregate demand - it is easier for workers to find a job. Thus, one should also observe a lower level of unemployment. Movements along the curve should be typically induced by the business cycle, while the position of the $\mathrm{BC}$ in the $(u, v)$ space is typically related to the degree of "frictions" in the market and, more generally, to its institutional setting. The closer the curve to the axes, the lower - ceteris paribus - market "frictions", cf. Nickell, Nunziata, Ochell, and Quintini (2001).

As far as co-movements between unemployment and wages are concerned, a second and complementary empirical regularity is the famous Phillips curve (i.e. negative relationship between changes of the wage rate and the unemployment rate); or the alternative Wage curve (Blanchflower and Oswald, 1994), which characterizes economies with a negative relationship between levels of the wage rate and the unemployment rate (Blanchard and Katz, 1997; Card and Hyslop, 1996; Flaschel, Kauermann, and Semmler, 2003). Empirical studies (Blanchflower and Oswald, 1994; Card, 1995) show that in homogeneous areas WC is in general valid, while PC is not ${ }^{\mathrm{d}}$. This empirical evidence seems to robustly hold across regions, countries, etc. but also among different institutional setups (Borsch-Supan, 1991; Bleakley and Fuhrer, 1997). The interpretation of a WC is quite controversial and bears some important theoretical implications. For instance, the competitive equilibrium framework cannot be invoked to account for WC emergence. In fact, a competitive labor market with all its canonical features would lead to a positive correlation between the unemployment rate and the wage rate. Climbing up a downward demand for labor schedule - i.e. raising wage - would indeed induce higher levels of unemployment, as the unmet supply of labor would grow.

A third fundamental aggregate regularity is the Okun curve (OC), which characterizes the interplay between labor markets and economic activity (Okun, 1962, 1970). Inspection of aggregate data typically shows that a decrease of one percentage point in the unemployment rate is associated - ceteris paribus - with a growth rate of GDP of about two to three percentage points (according to original Okun estimations). The standard interpretation runs in terms of under-utilization of labor resources with respect to full employment, carrying a more-than-proportional effect on economic activity (Prachowny, 1993; Attfield and Silverstone, 1997).

Mainstream economic theory has been trying to explain the foregoing aggregate regularities in the familiar equilibrium-cum-rationality framework, building the ex-

${ }^{\mathrm{c} O b s e r v a t i o n}$ of reliable proxies for actual vacancies entails many empirical problems, especially in Europe, see Solow (1998). For instance, one is typically bounded to observe only ex-ante vacancies (i.e. job openings). Ex-post vacancies (i.e. unfilled job openings) are much more affected by frictions than ex-ante ones and thus should be in principle preferred as object of analysis.

dAs the WC pertains to homogeneous data cells, one cannot "see it" in rough data. Panel data estimation must be performed in order to control for variables such as personal characteristics of workers, labor market institutions, "fixed" effects allowing to discriminate among sectors or regions, etc. . 
planation on the shoulder of hyper-rational, maximizing, representative worker and firm. Hence, any aggregate regularity is interpreted as the equilibrium outcome of some maximization exercises carried out by such agents.

A paradigmatic example of such modeling strategy can be found within the theoretical literature aimed at micro-founding and explaining the BC (Pissarides, 2000; Blanchard and Diamond, 1989). In these models, all search and matching, which in reality is an inherently dynamic process, is described in a static setting by means of a deterministic (aggregate) matching function, whose functional form and parametric assumptions tautologically imply a BC. The latter is treated as a static (long-run) equilibrium locus in the unemployment-vacancy space. Furthermore, one typically requires that all flows in and out of unemployment must always compensate $\mathrm{e}^{\mathrm{e}}$. Needless to say, this is at odds with any empirical observation.

Moreover, in order to get the desired results, many over-simplifying assumptions are required. First, the environment must be strictly stationary, ruling out any form of technological and organizational change, as well as any type of endogenous selection amongst firms and workers. Second, the presence of a hyper-rational, representative individual rules out the possibility of accounting for any form of heterogeneity across firms and workers. More than that: it excludes the very possibility of analyzing any interaction process among agents (cf. Kirman (1997) for a discussion). Third, as a consequence, one is prevented from studying the dynamic outcomes of multiple (reversible) decisions of hiring, firing, quitting, and searching which unfold over time.

Similar critiques also apply to the purported micro-foundations of Wage and Okun curves ${ }^{\mathrm{f}}$. Therefore, despite the existence of some competing, although not entirely persuasive, interpretations of each of the three aggregate regularities taken in isolation, the economic literature witnesses a dramatic lack of theories attempting to jointly explain Beveridge, Okun and Wage curves.

In the following, we begin to explore a radically different path and study the properties of a model where the most stringent assumptions of standard formalizations are abandoned and we explicitly account for the processes of out-of-equilibrium interactions among heterogeneous agents. We will try to provide an explicit microfoundation - within an evolutionary framework - of labor market dynamics regarding the processes governing e.g. job opening, job search, matching, bargaining, and wage setting.

Notice that the bottom line of the exercises belonging to the "pure equilibrium" genre is that they turn out to be unable, almost by construction, to account for involuntary unemployment or even endogenous changes in the "equilibrium" rates of unemployment.

\footnotetext{
e On the contrary, the model we present below allows the economy to evolve on a permanent disequilibrium path.

${ }^{\mathrm{f}}$ Cf. Hahn and Solow (1997) and Fagiolo, Dosi, and Gabriele (2004) for a thorough discussion on this and related points.
} 
It must be noticed that important advances, incrementally departing from the standard model, have nevertheless tried to incorporate agents' informational limitations, in order to account for phenomena such as endogenous fluctuations in aggregate activity and persistent involuntary unemployment (see e.g. the seminal work by Phelps and Winter (1970) and Phelps (1994)).

In addition, some contributions have attempted to introduce "endogenous matching" mechanisms to describe the (Walrasian) decentralized process governing the meetings between firms and workers in the labor market ${ }^{g}$. This is certainly a point our model takes on board in its full importance, and it does so through an explicit account of the (disequilibrium) unfolding of the interaction process.

In this respect, our model has three important antecedents in the labor market literature. First, the out-of-equilibrium, interaction-based, perspective that we pursue is a distinctive feature of "self-organization" labor market models ${ }^{\mathrm{h}}$. Second, the ACE model in Tesfatsion (2001) also assumes many heterogenous, interacting agents, characterized by "internal states" and behavioral rules, who exchange information in the market. Third, Aoki (2003) extends the ACE model of fluctuations and growth proposed in Aoki and Yoshikawa (2003) to allow for unemployment dynamics ${ }^{\mathrm{i}}$.

Notwithstanding many overlappings with "self-organization" and ACE formalizations, our model proposes advances, vis-à-vis the state of the art in this area, at least at four levels. First, it accounts for the co-evolutionary dynamics between the labor market and the product market. More specifically, we try to nest labor market interactions in what one could call a "general disequilibrium" framework with endogenous aggregate demand. This feature allows us to study also market properties associated with an endogenous business cycle. Second, we explicitly model (as endogenous processes) job opening, matching, wage bargaining, and wage setting. Third, we allow for technical progress and the ensuing macroeconomic growth. Fourth, in the analysis of the results we go beyond an "exercise in plausibility" and we explicitly compare the statistical properties of the simulated environments with empirically observed ones, specifically with respect to the emergence of Beveridge, Wage, and Okun curves.

gSee Lagos (2000), Peters (1991), Cao and Shi (2000), Burdett, Shi, and Wright (2001), Smith and Zenou (2003) and Julien, Kennes, and King (2000).

${ }^{\mathrm{h}}$ Cf. Lesourne (1992) and Laffond and Lesourne (2000). Self-organizing processes are discussed in Witt (1985).

iSimilarly to our model, co-evolution between product and labor market dynamics is explicitly taken into account and simulations allow to reproduce (albeit in some benchmark parameterizations) Okun curves. However, matching and wage bargaining are not incorporated in the model as endogenous processes. Therefore, no implications about Wage and Phillips curves can be derived from simulation exercises. 


\section{The Model}

Consider an economy composed of $F$ firms and $N$ workers $^{j}$. Time is discrete: $t=$ $0,1,2, \ldots$ and there is a homogeneous, perishable good $g$ whose price is $p_{t}>0$. In each period, a firm $i \in\{1, \ldots, F\}$ produces $q_{i t}$ units of good $g$ using labor as the sole input under a constant returns to scale (CRTS) regime:

$$
q_{i t}=\alpha_{i t} n_{i t},
$$

where $\alpha_{i t}$ is the current labor productivity of firm $i$ and $n_{i t}$ is the number of workers hired at $t$ by firm $i$. Workers are homogeneous as far as their skills are concerned. If the firm offers a contractual wage $w_{i t}$ to each worker, current profits are computed as:

$$
\pi_{i t}=p_{t} q_{i t}-w_{i t} n_{i t}=\left(p_{t} \alpha_{i t}-w_{i t}\right) n_{i t} .
$$

Contractual wages offered by firms to workers are the result of both a matching and a bargaining process. We assume that any firm $i$ has at time $t$ a "satisficing" wage $w_{i t}^{s}$ it wants to offer to any worker. Similarly, any worker $j \in\{1, \ldots, N\}$ has at time $t$ a "satisficing" wage $w_{j t}^{s}$ which he wants to get from firms. Moreover, any worker $j$ can only accept contractual wages if they are greater or equal to their reservation wage $w_{j}^{R}$, which we assume to be constant over time for simplicity.

We start by studying an economy where jobs last only one period. Hence, workers must search for a new job in any period. Job openings are equal to labor demand and, at the same time, to "ex-ante" vacancies. However, workers can be unemployed and firms might not satisfy their labor demand.

Let us turn now to a brief description of the flow of events in a generic timeperiod. We then move to a detailed account of each event separately.

\section{Dynamics}

Given the state of the system at the end of any time period $t-1$, the timing of events occurring in any time period $t$ runs as follows.

(1) Firms decide how many jobs they want to open in period $t$.

(2) Workers search for a firm posting at least one job opening and queue up.

(3) Job matching and bargaining occur: firms look in their queues and start bargaining with workers who have queued up (if any) to decide whether to hire them or not.

(4) After hiring, production takes place according to eq. (1). Aggregate supply and demand are then formed simply by aggregating individual supplies and

${ }^{\mathrm{j}}$ Notice that the higher the ratio between the number of workers and the number of firms $(N / F)$, the more economic activity is concentrated (i.e. a larger work force size must be employed in a smaller number of firms). Therefore, the higher $N / F$, the smaller the overall frictions in the hiring process. 
demands. Subsequently, a "pseudo-Walrasian" price setting occurs ${ }^{\mathrm{k}}$. We assume that the price of good $g$ at $t$ is given by:

$$
p_{t} Q_{t}=W_{t},
$$

where $Q_{t}=\sum_{i=1}^{F} q_{i t}$ is aggregate (real) output and $W_{t}=\sum_{j=1}^{N} w_{j t}$ is total wage. Thus, total wage equals aggregate demand, as we assume that workers spend all their income to eat good $g$ in any time period. Then, firms make profits:

$$
\pi_{i t}=\left(p_{t} \alpha_{i t-1}-w_{i t}\right) n_{i t} .
$$

(5) Given profits, firms undergo a selection process: those making negative profits $\left(\pi_{i t}<0\right)$ exit and are replaced by entrants, which, as a first approximation, are simply "average" firms (see below).

(6) Firms and workers update their satisficing wages $\left(w_{i t-1}^{s}\right.$ and $\left.w_{j t-1}^{s}\right)$.

(7) Finally, technological progress (if any) takes place. We assume that in each period labor productivity may increase at rates which are exogenous but firmspecific (see below).

\section{Job Openings}

At the beginning of period $t$, each firm creates a queue of job openings. Since in reality only ex-ante vacancies (i.e. new job positions) can be empirically observed, we will employ throughout the term job openings as a synonym of (ex-ante) vacancies. "Ex-post" vacancies will be computed as the number of unfilled job-openings.

Let us then call $v_{i t}$ the number of new positions opened by firm $i$ at time $t$. As far as the firm's decision about how many vacancies to open is concerned, we experiment with two alternative "behavioral" scenarios.

In the first one, a firm simply observes current (i.e. time $t-1$ ) price, quantity produced and the contractual wage offered, and sets vacancies $v_{i t}$ as:

$$
v_{i t}=\bar{v}_{i t-1}=\left\lceil\frac{p_{t-1} q_{i t-1}}{w_{i t-1}}\right\rceil,
$$

that is she creates a queue with a number of open slots equal to the "ceiling" of (i.e. the smallest integer larger than) the ratio between revenues and contractual wage offered in the last period. We call this job opening scenario the "Wild Market Archetype", in that no history-inherited institution or behavioral feature is built into the model.

In the second "behavioral" scenario (which we shall call the "Weak PathDependence" scenario), we introduce some rather mild path-dependence into the

\footnotetext{
${ }^{\mathrm{k}}$ We employ the simplifying assumption of an aggregate price setting mechanism to initially avoid any additional market frictions coming from e.g. a decentralized price setting procedure.
} 
vacancy setting. We suppose that: (a) jobs opened by any firm at time $t$ are a nondecreasing function of last-experienced profits growth rate; and (b) cannot exceed $\bar{v}_{i t-1}$. More formally:

$$
v_{i t}=\min \left\{\bar{v}_{i t-1}, v_{i t}^{*}\right\}
$$

and:

$$
v_{i t}^{*}=\left\{\begin{array}{l}
\left\lceil v_{i t-1}(1+|X|)\right\rceil, \text { if } \frac{\Delta \pi_{i t-1}}{\pi_{i t-1}} \geq 0 \\
\left\lceil v_{i t-1}(1-|X|)\right\rceil, \text { if } \frac{\Delta \pi_{i t-1}}{\pi_{i t-1}}<0
\end{array},\right.
$$

where $X$ is an i.i.d. random variable, normally distributed with mean zero and variance $\sigma_{v}^{2}>0$, and $\lceil x\rceil$ denotes the ceiling of $x$. Notice that the higher $\sigma_{v}$, the more firms react to any given profits growth rate by enlarging or shrinking their current queue size. Hence, a higher $\sigma_{v}$ implies higher sensitivity to market signals. Notice that, in both scenarios, firms always open at least one vacancy in each period.

\section{Job Search}

Similarly to job opening, we consider two "behavioral" scenarios for the job search procedure employed by workers to find a firm that has just opened new job positions. In the first one, called "No Search Inertia", each worker $j$ simply visits any firm $i$ in the market with a probability proportional to the last contractual wage $w_{i t-1}$ it offered. If the selected firm has places still available in the queue, the worker gets in and demands a wage equal to the "satisficing" one, i.e. $w_{j t-1}^{s}$.

In the second scenario, which we label "Search Inertia", we introduce some stickiness (loyalty) in firm visiting. If worker $j$ was employed by firm $i$ in period $t-1$, he visits first firm $i$. If $i$ still has places available in the queue, the worker gets in and demands $w_{j t-1}^{s}$. Otherwise, the worker employs the random rule above ("No Search Inertia") to select among the remaining $F-1$ firms.

In both scenarios, a worker becomes unemployed if he chooses a firm who has already filled all available slots in the queue ${ }^{1}$.

\section{Job Matching and Bargaining}

After workers have queued up, firms start exploring workers wage demands to match them with their desiderata. Suppose that, at time $t$, firm $i$ observes $0<m_{i t} \leq N$

\footnotetext{
${ }^{1}$ It must be noted that both job search scenarios only depict benchmark worlds and can be considered as starting points in our analysis. They indeed embody somewhat extreme assumptions about search costs and interaction structures. For instance, in the "No Search Inertia" scenario, workers' search costs are assumed to be negligible for the first visited firm, while they become infinite if workers visit more than one firm. Moreover, in the "Search Inertia" one, employed workers only recall their last employers. Alternative formulations of our basic model that we want to explore in the future include allowing for: (i) search costs which smoothly increase with the number of visited firms; (ii) the possibility for a worker to build through time networks of 'preferred' firms to guide his search.
} 
workers in the queue. Then, it will compute the average wage demanded by those workers:

$$
\bar{w}_{i t}=\frac{1}{m_{i t}} \sum_{h=1}^{m_{i t}} w_{j_{h} t-1}^{s}
$$

where $j_{h}$ are the labels of workers in $i^{\prime}$ s queue. Next, it sets the contractual wage for period $t$ as a linear combination of $\bar{w}_{i t}$ and the satisficing wage $w_{i t-1}^{s}$. Thus:

$$
w_{i t}=\beta w_{i t-1}^{s}+(1-\beta) \bar{w}_{i t},
$$

where $\beta \in[0,1]$ is an institutional parameter governing firms' strength in wage bargaining. A higher $\beta$ implies a higher strength on the side of the firm in wage setting. If $\beta=0$, firms just set contractual wage as the average of wages demanded by workers in the queue. If $\beta=1$, firms do not take into account at all workers' desiderata.

Once the firm has set the contractual wage at which it is willing to hire workers in the queue, any worker $j$ in the queue will accept the job only if $w_{i t}$ exceeds the reservation wage $w_{j}^{R}$.

As soon as a worker $j$ accepts the job, he temporarily changes his satisficing wage to keep up with the new (actual) wage earned, i.e. $w_{j t-1}^{s}=w_{i t}$. Similarly, a firm who has filled at least a job opening will replace $w_{i t-1}^{s}$ with $w_{i t}{ }^{\mathrm{m}}$.

Given the number of workers $n_{i t}$ hired by each firm, production, as well as price setting and profits determination occur as explained above. Ex-post firm $i$ 's vacancies are defined as $\widetilde{v}_{i t}=m_{i t}-n_{i t}$.

Selection, Exit, and Entry

Suppose that - given the new contractual wage, price $p_{t}$, and current productivity $\alpha_{i t-1}$ - firm $j$ faces negative profits, i.e. $p_{t} \alpha_{i t-1}<w_{i t}$. Then selection pressure makes firm $j$ exit the market.

Each exiting firm is replaced by a new firm which starts out with the average "characteristics" of those firms still in the market at $t$ (i.e. those making nonnegative profits) ${ }^{\mathrm{n}}$. Notice that this entry-exit process allows to keep an invariant number of $F$ firms in the economy at each $t$.

\section{Satisficing Wages Updating}

Surviving firms, as well as the $N$ workers, will then have the opportunity to revise their satisficing wage according to their perceptions about the outcome of market dynamics.

\footnotetext{
${ }^{\mathrm{m}}$ The new values of satisfying wages will then be employed in the updating process. Since satisfying wage can be interpreted as (myopic) expectations, satisfying wage updating plays in the model the role of an expectation formation process.

$\mathrm{n}$ All results we present in the next Section are robust to alternative assumptions concerning entry and exit.
} 
- Firms: We assume that each firm has an invariant desired ratio of filled to opened jobs $\rho_{i} \in(0,1]$ which it compares to the current ratio:

$$
r_{i t}=\frac{n_{i t}}{v_{i t}} .
$$

If firm $i$ hired too few workers (as compared to the number of job positions it has decided to open), then it might want to increase the wage it is willing to offer to workers. Otherwise, it might want to decrease it. We capture this simple rule by positing that:

$$
w_{i t}^{s}=\left\{\begin{array}{l}
w_{i t-1}^{s}(1+|Y|) \text { if } r_{i t}<\rho_{i} \\
w_{i t-1}^{s}(1-|Y|) \text { if } r_{i t} \geq \rho_{i}
\end{array}\right.
$$

where $Y$ is an i.i.d. random variable distributed as a standard normal. Notice that $w_{i t-1}^{s}$ is equal to $w_{i t}$ (i.e. contractual wage just offered) if the firm has hired at least one worker.

- Workers: If worker $j$ remains unemployed after matching and bargaining, he might want to reduce his satisficing wage (without violating the reservation wage threshold). Otherwise, he might want to demand a higher wage during the next bargaining session. We then assume that:

$$
w_{j t}^{s}=\left\{\begin{array}{cc}
\max \left\{w_{j}^{R}, w_{j t-1}^{s}(1-|Y|)\right\} & \text { if } j \text { unemployed } \\
w_{j t-1}^{s}(1+|Y|) & \text { if } j \text { employed }
\end{array}\right.
$$

where $Y$ is an i.i.d. random variable distributed as a standard normal. Again, $w_{j t-1}^{s}=w_{j t}$ if $j$ has been just hired.

\section{Technological Progress}

The last major ingredient of the model regards labor productivity dynamics. Here, we experiment with two "technological scenarios". In the first one ("No Technological Progress"), we study a system where labor productivity does not change through time (i.e. $\left.\alpha_{i t}=\alpha_{i}, \forall i\right)^{\circ}$. In the second scenario ("Technological Progress"), we allow for an exogenous, albeit firm-specific, dynamics of labor productivities. We start with initially homogeneous labor coefficients $\left(\alpha_{i 0}=\alpha\right)$ and we let them grow stochastically over time according to the following multiplicative process:

$$
\alpha_{i t}=\alpha_{i t-1}(1+Z)
$$

where $Z$, conditionally on $Z>0$, is an i.i.d. normally distributed random variable with mean 0 and variance $\sigma_{Z}^{2} \geq 0^{\mathrm{p}}$. The latter governs the opportunity setting in

\footnotetext{
${ }^{\circ}$ Labor productivity may in turn be either homogeneous across firms $\left(\alpha_{i}=\alpha\right)$ or not.

pHence, there is a probability 0.5 to draw a neutral labor productivity shock $(Z=0)$, while positive shocks are distributed as the positive half of a $N(0,1)$.
} 
the economy. The larger $\sigma_{Z}$, the more likely firms draw large productivity improvements. Notice that if we let $\sigma_{Z}=0$ we recover the "No Technological Progress" scenario $^{\mathrm{q}}$.

\section{Initial Conditions, Micro- and Macro-Dynamics}

The foregoing model, as mentioned, genuinely belongs to an evolutionary/ACE approach. Given its behavioral, bottom-up, perspective, one must resort to computer simulations to explore the behavior of the system ${ }^{\mathrm{r}}$.

The dynamics of the system depends on four sets of factors. First, we distinguish behavioral (e.g. concerning job opening and job search) and technological scenarios. We call such discrete institutional and technological regimes "system setups". Second, a choice of system parameters $\left(F / N, \sigma_{v}, \beta, \sigma_{Z}\right)$ is required (see Table 1). Third, one should explore the would-be importance of different initial conditions ${ }^{\mathrm{s}}$. Since simulations show that the latter do not dramatically affect the long-run properties of aggregate variables, we typically define a "canonical" set of initial conditions. All results presented below refer to this benchmark choice. Finally, individual updating by firms and workers induces a stochastic dynamics on micro-variables (e.g. contractual wages, desired production, desired employment, etc.). By aggregating these individual variables over firms and workers, one can study the properties of macro-dynamics for the variables of interest.

Table 1. System Parameters

\begin{tabular}{ccl}
\hline Parameter & Range & Meaning \\
\hline$N / F$ & $R_{++}$ & $\begin{array}{l}\text { Concentration of economic activity (Number } \\
\text { of Workers / Number of Firms) } \\
\text { Sensitivity to market signals in vacancy set- } \\
\sigma_{v}\end{array} R_{++}$ \\
$\beta$ & {$[0,1]$} & $\begin{array}{l}\text { tings (only in a Weak Path-Dependence Sce- } \\
\text { nario) } \\
\text { Labor-market institutional parameter govern- } \\
\text { ing the strength of firms in wage-setting } \\
\text { Technological parameter tuning the availabil- } \\
\text { ity of opportunities in the system (=0 means } \\
\text { no technological progress) }\end{array}$ \\
\hline
\end{tabular}

qTechnological progress, despite its firm-specific nature, is essentially exogenous. An alternative modeling strategy which we want to pursue in the future is to allow labor coefficients to change in a path-dependent way. For instance, one could assume that each $\alpha_{i t}$ is positively affected by: (a) past labor productivities of the firm where a new employed worker comes from; and/or (ii) the number of time-periods a given worker has spent working in the same firm $i$.

${ }^{\mathrm{r}}$ Simulation code is written in $\mathrm{C}++$ and is available from the Authors upon request.

${ }^{\mathrm{s}}$ In the model this implies defining initial values $\left(n_{i 0}, \alpha_{i 0}, w_{i 0}^{s}, w_{i 0}\right)_{i=1}^{F}$ for firms and $\left(w_{j 0}^{s}\right)_{j=1}^{N}$ for workers. Moreover, an initial price $p_{0}$, and some distributions for desired ratios $\left(\rho_{i}\right)_{i=1}^{F}$ and reservation wages $\left(w_{j}^{R}\right)_{j=1}^{N}$ have to be chosen. 
We will focus on unemployment:

$$
U_{t}=N-\sum_{i=1}^{F} n_{i t},
$$

total wages:

$$
W_{t}=\sum_{j=1}^{N} w_{j t},
$$

and (real) GDP:

$$
Q_{t}=\sum_{i=1}^{F} q_{i t},
$$

as well as its growth rate:

$$
h_{t}=\Delta \log \left(Q_{t}\right)
$$

\section{Simulation Results: Some Qualitative Evidence}

In this section, we firstly run simulation experiments in order to identify general setups and parameters choices under which the model is able to jointly replicate the three aggregate regularities characterizing labor markets dynamics and economic activity discussed in Section 2. In the following Section, we shall perform Monte Carlo exercises aimed at understanding how statistical properties of labor-market dynamics and economic activity change across different parameterizations and setups.

All simulation exercises we present in the paper refer to (and compare) four basic "system setups". Each "system setup" is characterized by a choice for behavioral/institutional assumptions (i.e. job opening and workers' job search) and a choice for the technological scenario (with or without technological change).

We experiment with the following two combinations of behavioral/institutional assumptions: (i) Walrasian Archetype (WA): We employ the "Wild Market Archetype" scenario as far as job opening is concerned and the "No Search Inertia" scenario for workers' job search; (ii) Institutionally-Shaped Environment (ISE): Firms open new job positions within a "Weak Path-Dependence" scenario, while workers search for a firm under the "Search Inertia" scenario.

Note that in the WA world, there is no path-dependence in job openings, nor in job search. Workers visit firms at random, while the latter open a number of new positions in each period without being influenced by past experienced profits. Conversely, in the ISE workers and firms face some path-dependence in job opening and job searching, as firms adjust job openings according to last profits growth and workers visit first the last firm in which they were employed. 
Each of the two foregoing behavioral choices is then associated to a technological scenario (with or without technological change) to get the four basic "system setups" under analysis ${ }^{\mathrm{t}}$.

We start by qualitatively investigating the emergence of Beveridge, Wage, and Okun curves in an economy characterized by the "Walrasian Archetype", i.e. a world where agents decide myopically and do not carry over past information. The system does not allow to recover any aggregate, statistically significant, negative relationship between vacancy and unemployment rates. Simulations show that the Beveridge curve fails to emerge for a quite large region of the system parameters $\left(F / N, \beta, \sigma_{Z}\right)$ space, cf. Figs. 1 and 2 for an example.

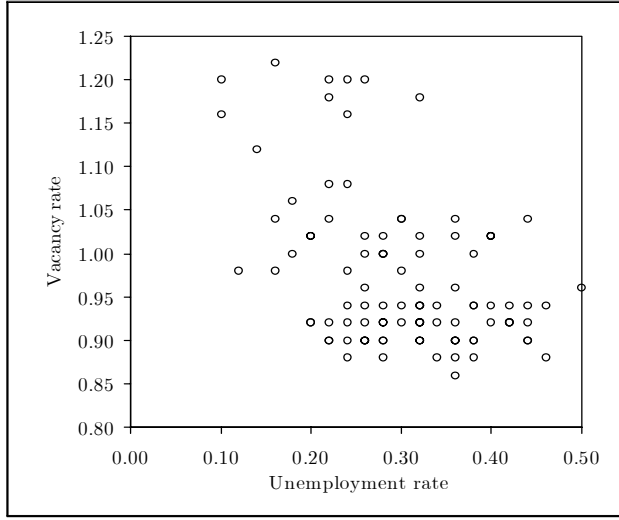

Fig. 1. Vacancy vs. Unemployment Rate in a "Walrasian Archetype" Economy without Technological Progress. Parameters: $N / F=5$, $\beta=0.5$.

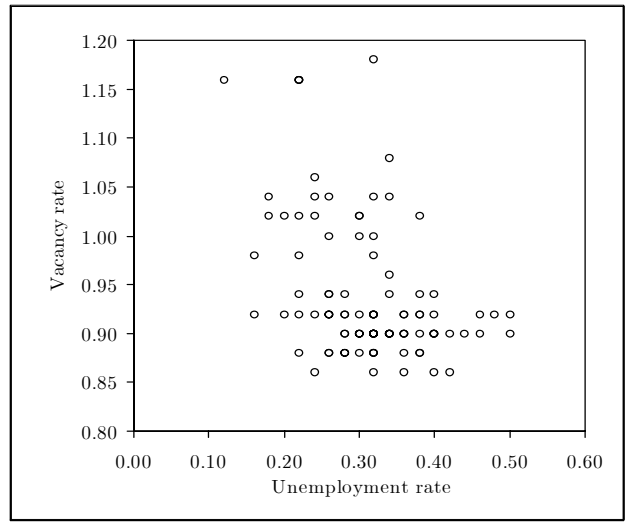

Fig. 2. Vacancy vs. Unemployment Rate in a "Walrasian Archetype" Economy with Technological Progress. Parameters: $N / F=5, \beta=$ $0.5, \sigma_{Z}=0.1$.

Conversely, both Wage and Okun curve robustly emerge no matter whether technological progress is shut down or not. Notice that if $\sigma_{Z}=0$, the economy works as a dynamic allocation device trying to match in a decentralized and imperfect way individual labor demand and supply for given resources. It is then easy to see that both Okun and Wage relationships are a consequence (and not an emergent property) of the joint assumptions of quasi-Walrasian price-setting and constant returns to scale. Indeed, from (1) and (3), one gets: $W_{t}=-p_{t} U_{t}+p_{t}\left(N-N_{t}+\right.$ $\left.\sum_{i} \alpha_{i} n_{i t}\right)$ and $Q_{t}=-U_{t}+\left(N-N_{t}+\sum_{i} \alpha_{i} n_{i t}\right)$. Thus, both curves are somewhat implied by the assumptions.

If on the contrary technological progress occurs in a WA scenario, there is no apparent reasons to expect both $\mathrm{OC}$ and $\mathrm{WC}$ to robustly emerge. Yet, as simulations show, they both characterize system dynamics for a large region of the parameter

${ }^{\mathrm{t}}$ In all exercises that follow, we set the econometric sample size $T=1000$. This time span is sufficient to allow for convergence of the recursive moments for all variables under study. 


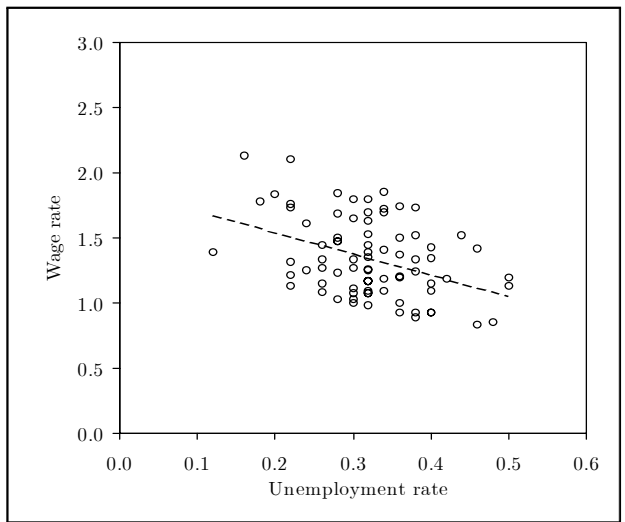

Fig. 3. Emergence of Wage curve in a "Walrasian Archetype" Economy with Technological Progress. Parameters: $N / F=5, \beta=0.5$, $\sigma_{Z}=0.1$

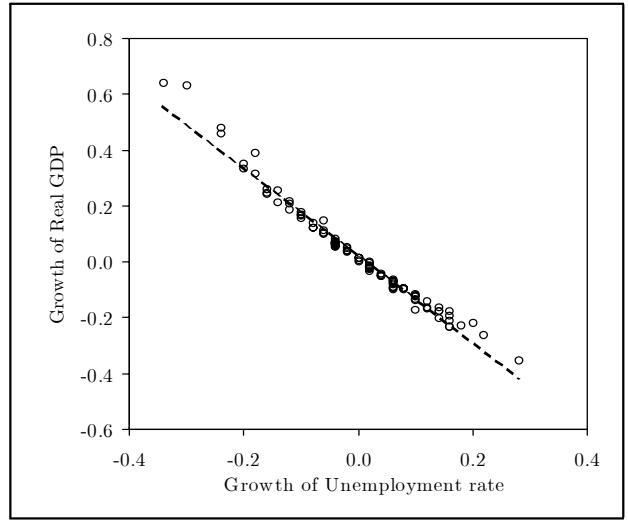

Fig. 4. Emergence of Okun curve in a "Walrasian Archetype" Economy with Technological Progress. Parameters: $N / F=5, \beta=0.5$, $\sigma_{Z}=0.1$.

space, even if no path-dependent behavior drives the economy (cf. Figs. 3 and 4).

Consider now an "Institutionally-Shaped Environment". Then, irrespective of the technological regime, the model is able to robustly generate Beveridge curves with statistically significant (negative) slopes: see for illustration Figs. 5 and 6 . Furthermore, when technological progress is present, both Wage and Okun curves still characterize macro-dynamics as robust, emergent, properties of the system, cf. Figs. 7 and 8.

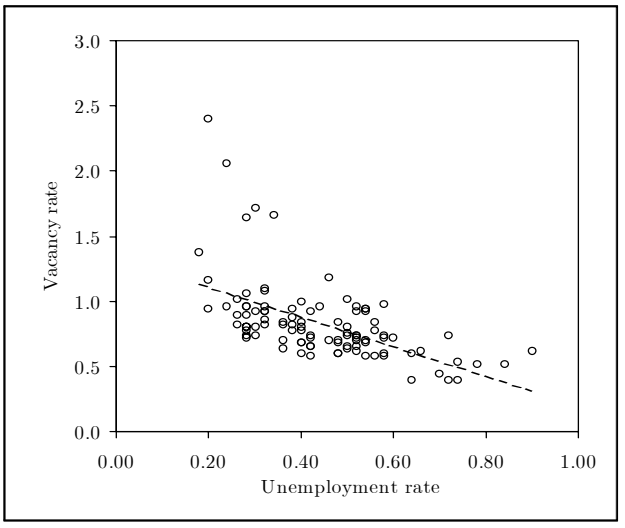

Fig. 5.

gence of Beveridge curve in a "InstitutionallyShaped" Environment without Technological Progress. Parameters: $N / F=5, \beta=0.5$.

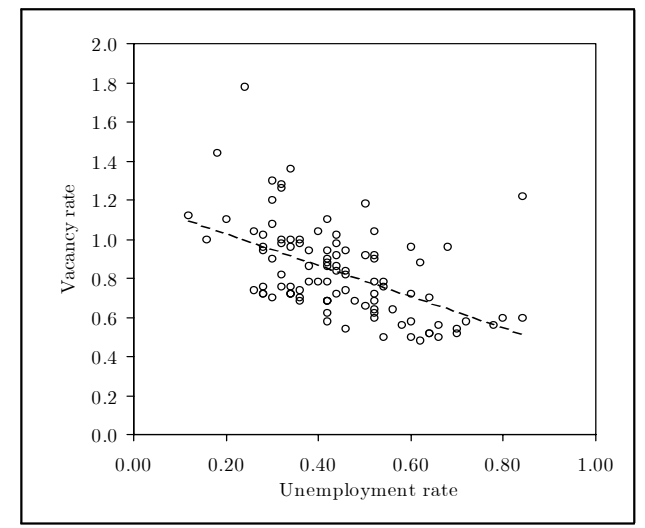

Fig. 6. Emergence of Beveridge curve in a "Institutionally- Shaped" Environment with Technological Progress. Parameters: $N / F=5$, $\beta=0.5, \sigma_{Z}=0.1$ 


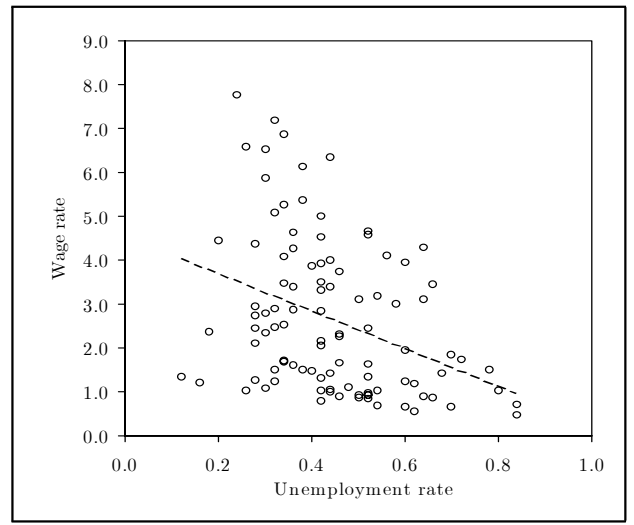

Fig. 7. Emergence of Wage curve in a "Institutionally-Shaped" Environment with Technological Progress. Parameters: $N / F=5$, $\beta=0.5, \sigma_{Z}=0.1$.

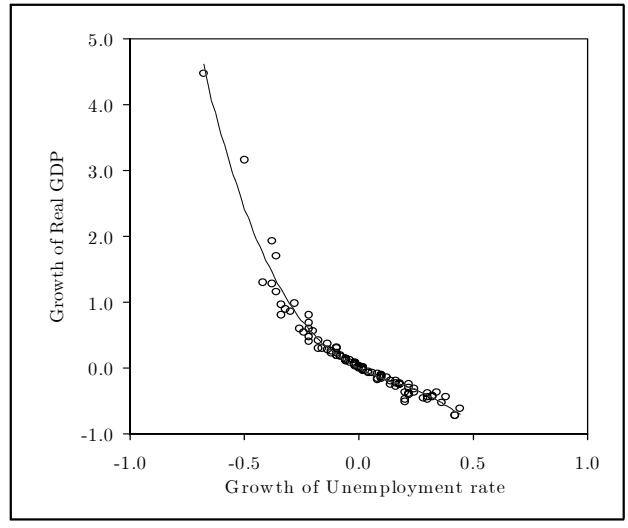

Fig. 8. Emergence of Okun curve in a "Institutionally-Shaped" Environment with Technological Progress. Parameters: $N / F=5$, $\beta=0.5, \sigma_{Z}=0.1$.

\section{Monte Carlo Experiments}

The set of qualitative results presented in the last Section suggest that some pathdependence seems to be a necessary condition for a Beveridge relationship. Moreover, a standard Okun curve seems to be in place even when technological progress persistently boosts available production capacity. Finally, despite persistent heterogeneity arising endogenously from labor productivity dynamics, Phillips-curve type of regularities are typically rejected by the simulated data in favor of a Wage curve relationship.

To check whether these qualitative results are robust to changes in system parameters, we turn now to a more detailed Monte Carlo analysis. We discuss two sets of exercises. First, we ask whether the three regularities we are interested in, robustly emerge in each of the four main "setups" under study. To this end, we generate $M$ independent (Monte Carlo) simulations for each choice of relevant parameters over a sufficiently fine grid. We then study the moments of the distributions of the statistics of interest. We focus in particular on test statistics for the significance of coefficients in Beveridge and Okun regressions, the magnitude of Okun coefficient, as well as test statistics discriminating between Wage and Phillips curves.

Second, we will perform some simple "comparative dynamics" exercises to investigate what happens to emergent regularities when one tunes system parameters within each "setup". We are in particular interested in detecting shifts (if any) in the Beveridge curve and changes in Okun coefficients. Once again, we will discuss the outcome of Monte Carlo statistics coming from independent time-series simulation 
runs for any given parametrization ${ }^{\mathrm{u}}$.

\section{Emergence of Aggregate Regularities: Robustness Tests}

To begin with, consider the emergence of Beveridge curves. Consider, for any setup under analysis, a given parametrization. Following existing empirical literature, we computed, for each of $M$ independent simulated time-series, estimates (and $R^{2}$ ) for the simple time-series regression:

$$
u_{t}=b_{0}+b_{1} v_{t}+\epsilon_{t},
$$

where $\epsilon_{t}$ is white-noise, $u_{t}$ is the unemployment rate and $v_{t}$ is the vacancy rate (both defined as activity rates). We then computed Monte Carlo statistics (e.g. average) of estimates $\widehat{b_{1}}$ and goodness-of-fit $R^{2}$, together with the percentage of rejections for the test $b_{1}=0$ (i.e. a proxy for the likelihood of $\mathrm{BC}$ emergence, in case of a negative estimate). By repeating this exercise as parameters change within a given system setup (WA vs. ISE), one is able to investigate Beveridge curves emergence, how large are their slopes, and how good is the correspondent linear fit on averagev ${ }^{\mathrm{v}}$.

Notice first that, in a WA, the likelihood of the emergence of a $\mathrm{BC}$ is quite low. As Fig. 9 shows, the percentage of rejections of $H_{0}: b_{1}=0$ is almost always below $50 \%$ as we tune firms' strength in wage bargaining $(\beta)$ and technological opportunities $\left(\sigma_{Z}\right)$. Accordingly, the estimated slope does not dramatically change across the parameter space, ranging from -0.938 and -0.263 (not shown). In particular, technological progress seems to favor $\mathrm{BC}$ emergence: the higher $\sigma_{Z}$, the larger the percentage of rejections and the larger the goodness of fit of the correspondent regression (cf. Fig. 10). To see why this happens, recall that a stronger technological boost induces firms to open more vacancies, which the system seems to be able to more easily fill. When technology is strong enough, a lower $\beta$ also appears to favor the emergence of a $\mathrm{BC}$, even if this effect turns out to be milder than the technological one.

If on the contrary the economy is characterized by an "institutionally-shaped environment", the percentage of rejections is almost always close to $100 \%$ across the entire $\left(\sigma_{v}, \sigma_{Z}, \beta\right)$ space and the average estimated slope is negative (not shown). Thus, unlike in a WA economy, the presence of some frictions and path-dependence in the institutional and behavioral settings allows a $\mathrm{BC}$ to robustly emerge. Here, firms' bargaining strength $(\beta)$ appears to have a strong impact on the goodness of fit. In fact, when $\beta$ is low $(\beta=0.1)$, the linear fit turns out to better describe the vacancy-unemployment relationship (cf. Fig. 11) than in the case when firms' bargaining strength is high $(\beta=1.0)$, see Fig. 12. In this latter case, however, a

uAll Monte Carlo experiments are undertaken using a Monte Carlo sample size $M=100$. Initial conditions are always kept fixed (see above).

${ }^{v}$ Standard errors of estimates, as well as Monte Carlo (across simulations) standard deviations of all statistics of interest appear to be very small. Therefore, we do not report here confidence intervals. 


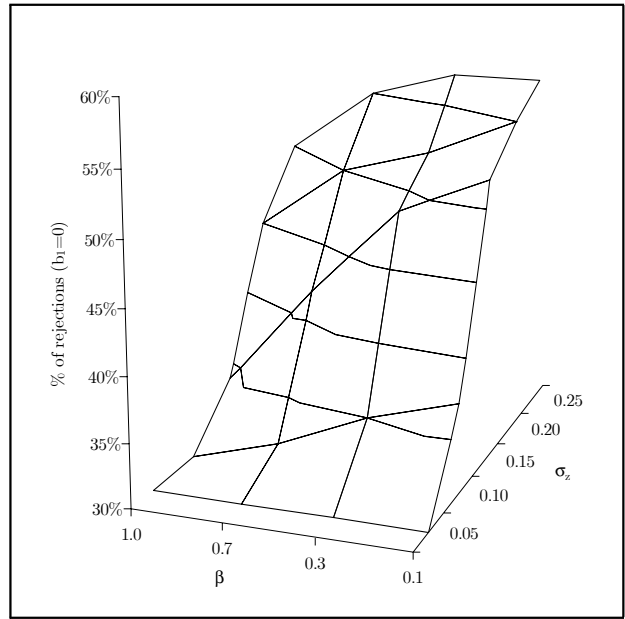

Fig. 9. Percentage of rejections of $H_{0}: b_{1}=0$ for the Beveridge Regression $u_{t}=b_{0}+b_{1} v_{t}+\epsilon_{t}$ in a "Walrasian Archetype" as firms' strength in wage-setting $(\beta)$ and technological opportunities $\left(\sigma_{Z}\right)$ change $(N / F=5)$.

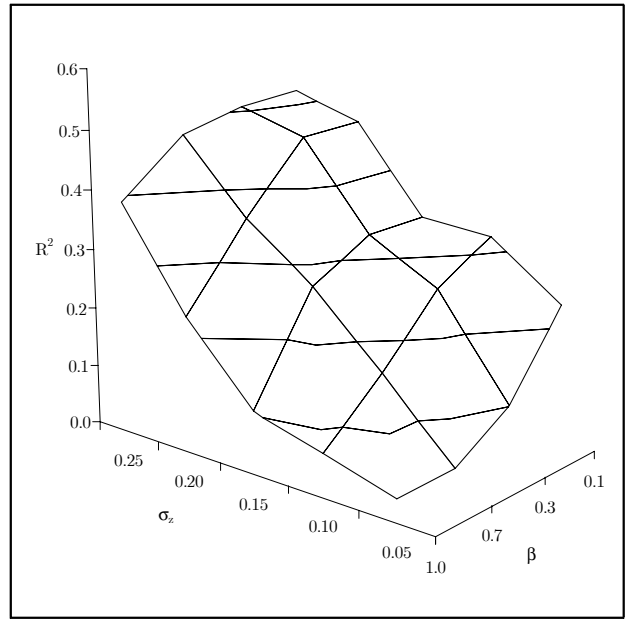

Fig. 10. Goodness of fit $\left(R^{2}\right)$ of Beveridge Regression $u_{t}=b_{0}+b_{1} v_{t}+\epsilon_{t}$ in a "Walrasian Archetype" as firms' strength in wagesetting $(\beta)$ and technological opportunities $\left(\sigma_{Z}\right)$ change $(N / F=5)$.

higher sensitivity to market signals $\left(\sigma_{v}\right)$ favors the emergence of well-shaped BC. Indeed, in presence of technical progress, a larger $\sigma_{v}$ allows firms to turn higher profits in a higher number of vacancies, which are more easily filled when firms are stronger in the wage-bargaining process.

While the Beveridge curve tends to robustly emerge only in an "institutionallyshaped" economy, simulations show that a Wage curve always characterizes our system in all four setups. In particular, statistical tests aimed at discriminating between a Phillips and a Wage world, show that the latter is almost always preferred. Following Card (1995), we perform the lagged regression:

$$
\Delta \log \widetilde{W}_{t}=g_{t}+a_{1} \log u_{t}+a_{2} \log u_{t-1}+\Delta e_{t}
$$

where $\widetilde{W}_{t}$ is the wage rate, $u_{t}$ is the unemployment rate, $g_{t}$ is a time trend, and first-differencing is taken to avoid serial correlation in $e_{t}$. As Card (1995) shows, the Wage curve hypothesis implies $a_{1}=-a_{2}$ (together with $a_{1}<0$ ), while the Phillips curve hypothesis requires $a_{2}=0$. Table 2 reports Monte Carlo testing exercises in our four setups for a benchmark parametrization ${ }^{\mathrm{w}}$. Notice that the percentage of rejections of a Phillips world is quite high, while we tend not to reject the hypothesis that wage levels are negatively correlated with unemployment rates in almost all simulations.

${ }^{\mathrm{w}}$ As far as the emergence of Okun and Wage curves are concerned, one does not detect any statistically significant differences in percentage of rejections when parameters change across different system setups. See below for some considerations on shifts of Beveridge and Okun curves across different parameterizations. 


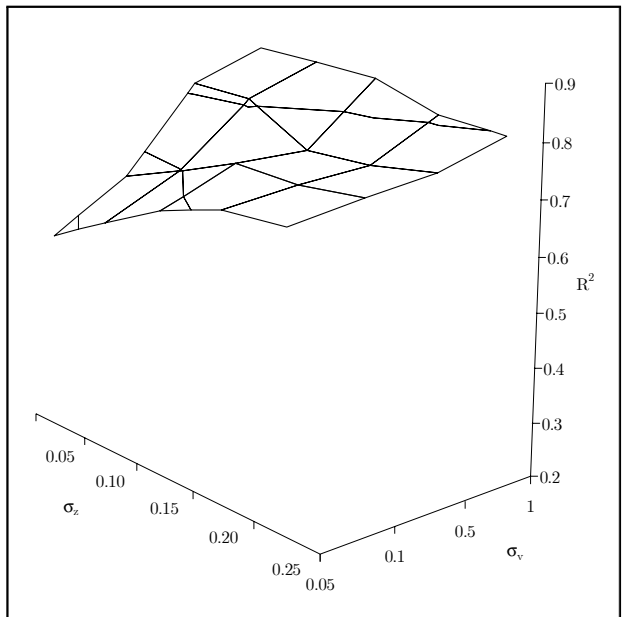

Fig. 11. Goodness of fit $\left(R^{2}\right)$ of Beveridge Regression $u_{t}=b_{0}+b_{1} v_{t}+\epsilon_{t}$ in a "Institutionally-shaped Environment" characterized by a low firms' strength in wage-setting $(\beta=0.1)$ as firms' sensitivity to market signals $\left(\sigma_{v}\right)$ and technological opportunities $\left(\sigma_{Z}\right)$ change $(N / F=5)$.

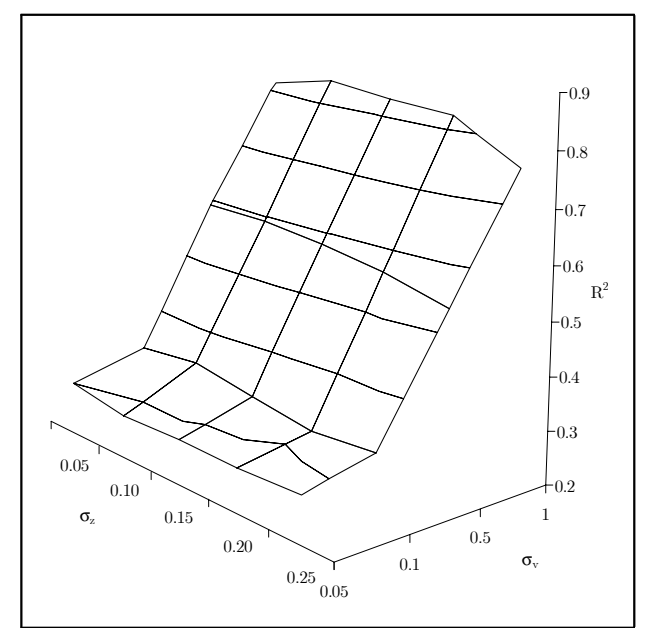

Fig. 12. Goodness of fit $\left(R^{2}\right)$ of Beveridge Regression $u_{t}=b_{0}+b_{1} v_{t}+\epsilon_{t}$ in a "Institutionally-shaped Environment" characterized by a high firms' strength in wagesetting $(\beta=1.0)$ as firms' sensitivity to market signals $\left(\sigma_{v}\right)$ and technological opportunities $\left(\sigma_{Z}\right)$ change $(N / F=5)$.

The $R^{2}$ is very high in all setups. This might be an expected result when $\sigma_{Z}=0$, because without technological progress a Wage curve follows from price-setting and constant returns. However, when $\sigma_{Z}>0$ the goodness-of-fit remains high (and standard errors very low). Our model seems to allow for well-behaved Wage curves also when technological progress induces persistent heterogeneity in labor productivity dynamics. Furthermore, a quite general and robust result (see also below) concerns the effect of technological progress upon the slope of the curve. As discussed above, the latter is expected to be around -1.0 when $\sigma_{Z}=0$, but nothing can in principle be said about the expected slope when $\sigma_{Z}>0$. Our results suggest that, even when technological progress is present, the Wage curve robustly emerges. Indeed, wage rates become even more responsive to unemployment than in the $\sigma_{Z}=0$ case.

Alike the Wage curve, the Okun curve, too, turns out to be a robust outcome of our labor market dynamics. Evidence of this effect simply appears by linearly regressing GDP growth rates against changes in the rates of unemployment:

$$
\Delta \log \left(Q_{t}\right)=c_{0}+c_{1} \Delta \log \left(u_{t}\right)+\epsilon_{t} .
$$

We computed Monte Carlo estimates of the Okun coefficient $c_{1}$ and we tested for $H_{0}: c_{1}=0$ (i.e. the emergence of an Okun curve - as long as $c_{1}<0$ ), see Table 3 for an example. Our economy allows for an Okun relationship in all settings, especially when technological progress is present. Again, this might be considered as a nottoo-surprising result when $\sigma_{Z}=0$, but it becomes a truly emergent property when 
Table 2. Emergence of the Wage curve in alternative setups.

\begin{tabular}{ccccc}
\hline & \multicolumn{4}{c}{ Setups } \\
& $\sigma_{Z}=0$ & $\sigma_{Z}>0$ & $\sigma_{Z}=0$ & $\sigma_{Z}>0$ \\
\hline MC Average of $\widehat{a_{1}}$ & -0.814 & -1.643 & -1.019 & -2.329 \\
MC Average of $\widehat{a_{2}}$ & $(0.025)$ & $(0.093)$ & $(0.072)$ & $(0.225)$ \\
$R^{2}$ & 0.781 & 1.520 & 0.977 & 2.134 \\
& $(0.019)$ & $(0.083)$ & $(0.020)$ & $(0.169)$ \\
& 0.985 & 0.906 & 0.978 & 0.914 \\
$\%$ of rejections $\left(H_{0}: a_{2}=0\right)$ at $5 \%$ & $(0.003)$ & $(0.023)$ & $(0.017)$ & $(0.026)$ \\
$\%$ of rejections $\left(H_{0}: a_{1}=-a_{2}\right)$ at $5 \%$ & $100 \%$ & $99 \%$ & $99 \%$ & $100 \%$ \\
\hline
\end{tabular}

Note: WA = "Walrasian Archetype". ISE = "Institutionally- Shaped Environment". Functional form tested: $\Delta \log \widetilde{W}_{t}=g_{t}+a_{1} \log u_{t}+a_{2} \log u_{t-1}+\Delta e_{t}$. Rejecting Phillips curve hypothesis means rejecting $H_{o}^{\prime}: a_{2}=0$. Rejecting Wage curve hypothesis means rejecting $H_{o}^{\prime}: a_{1}=-a_{2}$. Monte Carlo Standard Errors in parentheses. Monte Carlo sample size $M=100$. Benchmark parametrization: $N / F=5, \beta=0.5, \sigma_{Z}=0.1$ (when $\left.>0\right), \sigma_{v}=0.1$ (under ISE).

technological progress fuels the economy.

The absolute value of the Okun coefficient is larger than one (and indeed close to Attfield and Silverstone (1997) empirical estimates), implying some emergent aggregate dynamic increasing returns to labor. The effect becomes stronger when an ISE is assumed: Monte Carlo averages of the Okun coefficient range from -2.196 to -3.072 .

Table 3. Emergence of the Okun curve in alternative setups.

\begin{tabular}{ccccc}
\hline & \multicolumn{4}{c}{ Setups } \\
& $\sigma_{Z}=0$ & $\sigma_{Z}>0$ & $\sigma_{Z}=0$ & $\sigma_{Z}>0$ \\
\hline MC Average of $\widehat{c_{1}}$ & -2.064 & -2.196 & -2.635 & -3.072 \\
$R^{2}$ & $(0.042)$ & $(0.047)$ & $(0.068)$ & $(0.063)$ \\
& 0.939 & 0.925 & 0.928 & 0.936 \\
& $(0.026)$ & $(0.060)$ & $(0.064)$ & $(0.025)$ \\
Max of Tail Prob. Distrib. for $H_{0}: c_{1}=0$ & 0.000 & 0.001 & 0.000 & 0.001 \\
\% of rejections $\left(H_{0}: c_{1}=0\right)$ at $5 \%$ & $100 \%$ & $99 \%$ & $100 \%$ & $99 \%$ \\
\hline
\end{tabular}

Note: WA = "Walrasian Archetype". ISE = "Institutionally- Shaped Environment". Estimation of $\Delta \log \left(Q_{t}\right)=c_{0}+c_{1} \Delta \log \left(u_{t}\right)+\epsilon_{t}$. Monte Carlo Standard Errors in parentheses. Monte Carlo sample size $M=100$. Benchmark parametrization: $N / F=5$, $\beta=0.5, \sigma_{Z}=0.1$ (when $\left.>0\right), \sigma_{v}=0.1$ (under ISE).

Notice that one did not assume any increasing returns regime at the individual firm level. In fact, firms produce using constant returns production functions, see (1). Moreover, no Phillips curve relationships is in place: our economy typically displays a negative relationship between unemployment rates and wage levels. This 
suggests that aggregation of imperfect and persistently heterogeneous behaviors lead to macro-economic dynamic properties that were not present at the individual level. Therefore, aggregate dynamic increasing returns emerge as the outcome of aggregation of dynamic, interdependent, microeconomic patterns (Forni and Lippi, 1997).

\section{Some Comparative Dynamics Monte Carlo Exercises}

We turn now to a comparative dynamics Monte Carlo investigation of the effect of system parameters on emergent aggregate regularities. We focus on the "institutionally-shaped" setup, wherein the economy robustly exhibits well-behaved Beveridge, Wage, and Okun curves, and we study what happens under alternative parameter settings. In particular we compare parameter setups characterized by:

(1) low vs. high $N / F$ ratio (i.e. degrees of concentration of economic activity);

(2) low vs. high $\sigma_{v}$ (i.e. sensitivity to market signals in the way firms set their vacancies);

(3) low vs. high $\beta$ (i.e. firms' bargaining strength in wage setting);

(4) low vs. high $\sigma_{Z}$ (technological opportunities).

We first ask whether a higher sensitivity to market signals in vacancy setting induce detectable shifts in aggregate regularities. As Table 4 shows, the smaller $\sigma_{v}$, the stronger the revealed increasing dynamic returns: GDP growth becomes more responsive to unemployment growth and the Okun curve becomes steeper. Notice that $\sigma_{v}$ can also be interpreted as an inverse measure of path-dependence in firms' vacancy setting. The smaller $\sigma_{v}$, the more firms tend to stick to last-period job openings. Therefore, a smaller path-dependence implies a steeper Okun relation.

Table 4. Shifts in the Okun coefficient in an "Institutionally- Shaped Environment" under alternative parameter settings.

\begin{tabular}{ccccc}
\hline & \multicolumn{4}{c}{ ISE Setup } \\
& $\sigma_{v}=1.0$ & (HSMS) & $\sigma_{v}=0.2$ (LSMS) \\
& $\sigma_{Z}=0$ & $\sigma_{Z}>0$ & $\sigma_{Z}=0$ & $\sigma_{Z}>0$ \\
\hline MC Average of $\widehat{c_{1}}$ & -2.700 & -2.960 & -2.900 & -3.270 \\
$R^{2}$ & $(0.082)$ & $(0.085)$ & $(0.064)$ & $(0.060)$ \\
& 0.928 & 0.936 & 0.939 & 0.925 \\
& $(0.064)$ & $(0.025)$ & $(0.026)$ & $(0.060)$ \\
Max of Tail Prob. Distrib. for $H_{0}: c_{1}=0$ & 0.001 & 0.001 & 0.000 & 0.001 \\
\% of rejections $\left(H_{0}: c_{1}=0\right)$ at $5 \%$ & $100 \%$ & $99 \%$ & $100 \%$ & $99 \%$ \\
\hline
\end{tabular}

Note: HSMS: High Sensitivity to Market Signals. LSMS: Low Sensitivity to Market Signals. Estimation of $\Delta \log \left(Q_{t}\right)=c_{0}+c_{1} \Delta \log \left(u_{t}\right)+\epsilon_{t}$. Monte Carlo Standard Errors in parentheses. Monte Carlo sample size $M=100$. Benchmark parametrization: $N / F=$ $5, \beta=0.5, \sigma_{Z}=0.1$.

Analogously, we investigate the impact on the $\mathrm{BC}$ of simultaneously increasing $N / F$ (i.e. increasing $N$ for a given $F$ ) and $\sigma_{v}$ (i.e. firms' "sensitivity to market 
signals"). Notice that a higher concentration allows firms - ceteris paribus - to more easily fill their vacancies. Similarly, the higher $\sigma_{v}$, the more firms are able to react to aggregate conditions and correspondingly adjust vacancies. Therefore, one might be tempted to interpret economies characterized by high values for both $N / F$ and $\sigma_{v}$ as "low friction" worlds, and expect the BC curve to lie closer to the axes. Notice, however, that in our model an "indirect" effect is also present. If labor demand is very low (e.g. because the economy is in a recession), then the unemployment rate might be high irrespective of the value of $N / F$. Moreover, if $\sigma_{v}$ is high, firms will fire more workers during downswings, thus inducing a sort of "accelerator" effect on the recession. Hence, the consequences on the BC of assuming a larger market concentration and a higher sensitivity to market signals are ex-ante ambiguous: if the "indirect" effects dominate, we should observe various combinations between shifts to the right and "business-cycle" movements along the curve.

Notwithstanding all that, Monte Carlo simulations show that the model is able to reproduce the predicted shifts in the BC. We observe (cf. Table 5) that as $N / F$ and $\sigma_{v}$ both increase in a ISE economy, Monte Carlo averages of estimated intercepts stay constant, while the $\mathrm{BC}$ becomes, on average, steeper (and thus closer to the origin). A steeper BC implies that firms adaptively learn to open less vacancies and to adjust their filled-to-open vacancy ratios in response to market signals.

Table 5. Shifts in the Beveridge curve in an "Institutionally- Shaped Environment" under alternative parameter settings.

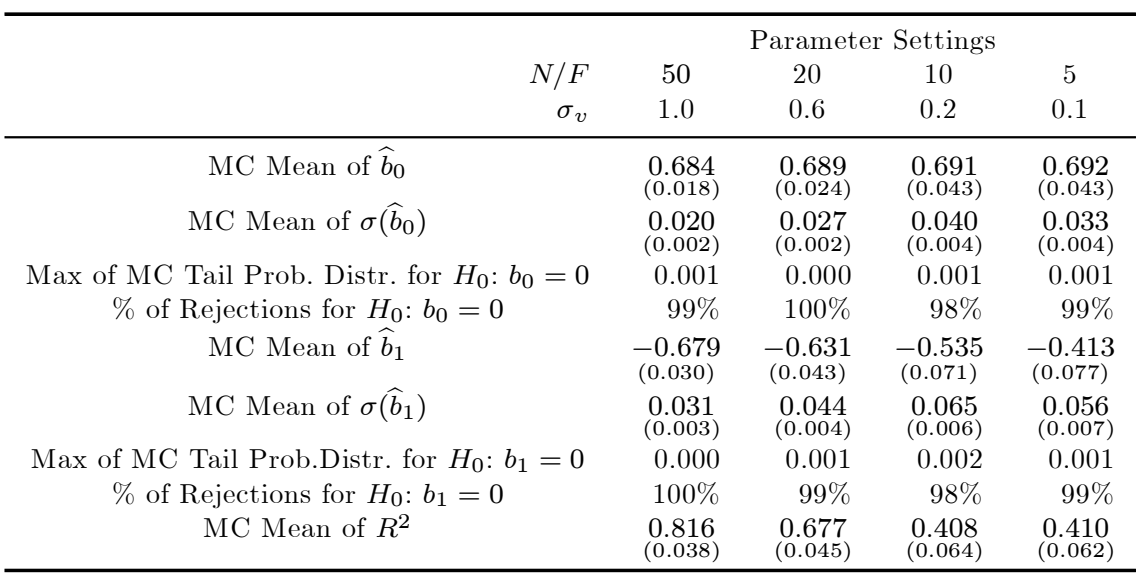

Note: Setups: (i) Concentration of economic activity $N / F$; (ii) sensitivity to market signals $\sigma_{v}$. Estimation of $u_{t}=b_{0}+b_{1} v_{t}+\epsilon_{t}$. Monte Carlo Standard Errors in parentheses. Monte Carlo sample size $M=100$. Benchmark parametrization: $\beta=0.5$. No technical progress is assumed to focus on BC shifts for given resources.

Second, we explore what happens to (within-simulation) average and standard 
deviation of GDP growth time-series ${ }^{\mathrm{x}}$ when both $\sigma_{v}$ and firms' bargaining strength $\beta$ are allowed to vary. Recall that the higher $\beta$, the less firms take into account workers satisficing wages when they decide their contractual wage. Figs. 13 and 14 show Monte Carlo means of average and standard deviation of GDP growth rates. We find that the higher firms' bargaining strength, the smaller both average growth rates and their variability. Thus, allowing for some bargaining power on the workers' side implies better aggregate performance, but also more fluctuations. Furthermore, if firms are less responsive to market signals (e.g. they employ a path-dependent vacancy setting rule) the economy enjoys persistently higher average growth rates and persistently smaller fluctuations.

Finally, we assess the consequences of "fueling" the economy with higher technological opportunities (i.e. higher $\sigma_{Z}$ ) for different levels of $\beta$ (and setting $\sigma_{v}$ to an intermediate level). While a higher $\sigma_{Z}$ implies higher average growth rates in all parameter settings (Fig. 15), a stronger bargaining power for workers still implies better aggregate performances. Together, more technological opportunities also entail a higher volatility in the growth process (see Fig. 16). Volatility can be weakened if one increases firm strength in wage bargaining.

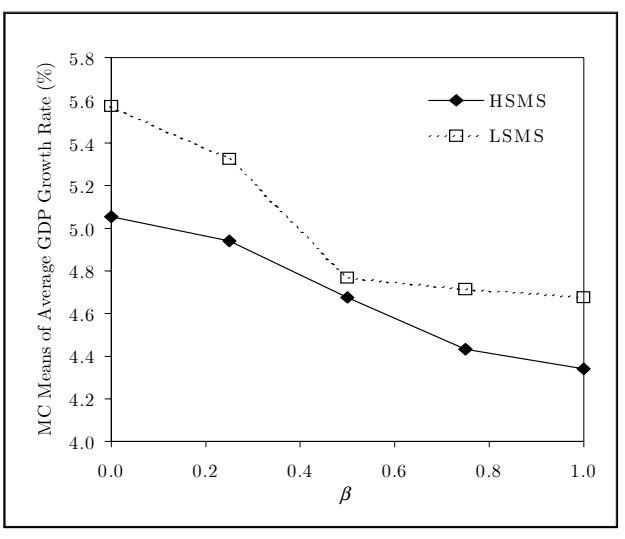

Fig. 13. Monte Carlo Means of (withinsimulation) Average Real GDP Growth Rates as a function of firms strength in wage bargaining $(\beta)$. LSMS vs. HSMS: Low $\left(\sigma_{v}=0.1\right)$ vs. High $\left(\sigma_{v}=1.0\right)$ sensitivity to market signals in vacancy setting. "Institutionally-Shaped" Environment. Parameters: $N / F=5, \sigma_{Z}=0.1$.

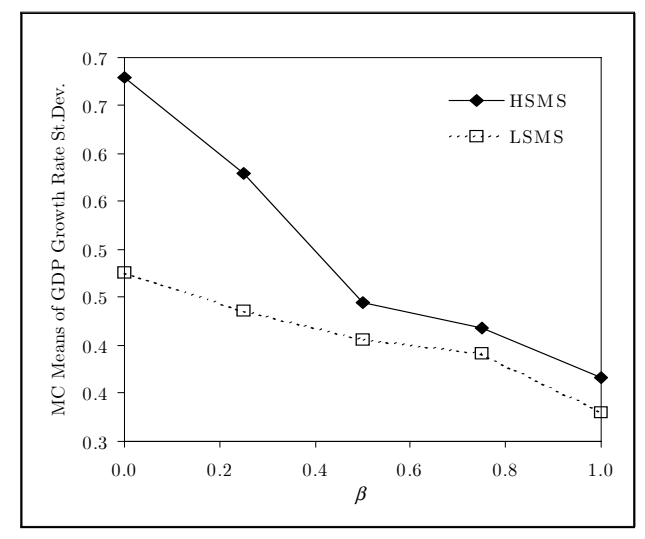

Fig. 14. Monte Carlo Means of (withinsimulation) Standard Deviation of Real GDP Growth Rates as a function of firms strength in wage bargaining $(\beta)$. LSMS vs. HSMS: Low $\left(\sigma_{v}=0.1\right)$ vs. High $\left(\sigma_{v}=1.0\right)$ sensitivity to market signals in vacancy setting. "Institutionally-Shaped" Environment. Parameters: $N / F=5, \sigma_{Z}=0.1$.

x That is, we compute average and standard deviation of GDP growth rates within a simulation $\left\{h_{t}, t=1, \ldots, T\right\}, h_{t}=\Delta \log Q_{t}$. 


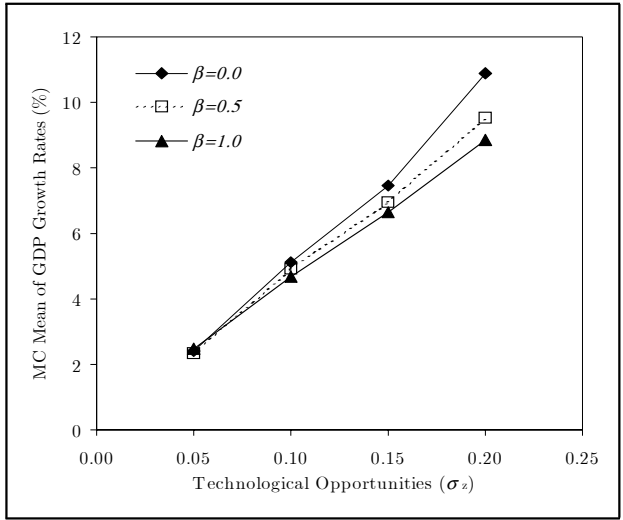

Fig. 15. Monte Carlo Means of (withinsimulation) Average Real GDP Growth Rates as a function of technological opportunities $\left(\sigma_{Z}\right)$ and firms strength in wage bargaining $(\beta)$. "Institutionally-Shaped" Environment. Parameters: $N / F=5, \sigma_{v}=0.1$.

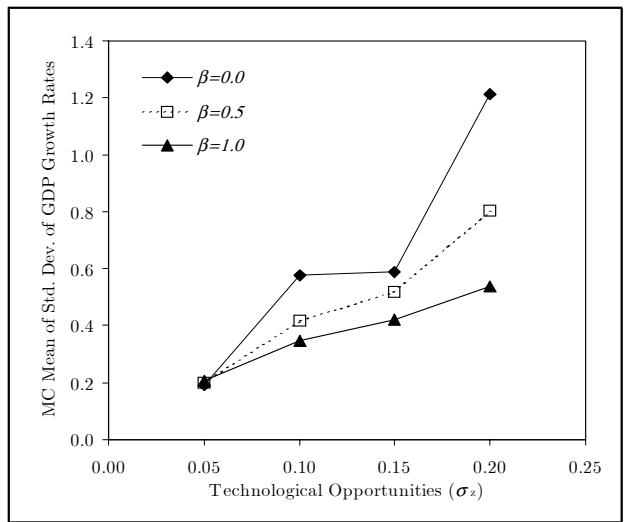

Fig. 16. Monte Carlo Means of (withinsimulation) Standard Deviation of Real GDP Growth Rates as a function of technological opportunities $\left(\sigma_{Z}\right)$ and firms strength in wage bargaining $(\beta)$. "Institutionally-Shaped" Environment. Parameters: $N / F=5, \sigma_{v}=0.1$.

\section{Conclusions}

In this paper, we have presented an evolutionary model of output and labor market dynamics describing from the bottom-up individual behaviors of multiple firms and workers and their interactions. In particular, we have explicitly modeled from an agent-based perspective the processes of vacancy setting, as well as matching, wage bargaining, and wage setting.

We have assumed that firms produce a homogeneous, perishable, good under constant returns to labor, enjoy labor productivity improvements thanks to technological progress, and undergo a selection process shaped by their revealed competitiveness (which is also affected by their hiring and wage-setting behaviors). Both demand and price formation are modeled as endogenous processes.

The interplay between labor and output markets allows one to appreciate the relationships between the business cycle and unemployment. Such an interplay provides a joint, evolutionary, interpretation of some of the most important aggregate stylized facts in labor market dynamics and the business cycle, such as the Beveridge curve, the Wage curve, and the Okun curve.

Simulations show that Beveridge, Wage and Okun curves can be jointly generated by our model as emergent properties under quite broad behavioral and institutional settings. Moreover, the emergent Okun curves exhibit aggregate dynamic increasing returns notwithstanding firms employ linear production functions.

Monte Carlo simulations also indicate that statistically detectable shifts in Okun and Beveridge curves emerge as the result of changes in institutional, behavioral, and technological parameters. For example, a higher concentration of market activity (i.e. a higher number of workers per firm) and a higher sensitivity to market 
signals in firms' vacancy setting rules imply Beveridge curves which lie closer to the axes.

Finally, the model generates quite sharp predictions about how the average aggregate performance (and volatility) of the system changes in alternative behavioral, institutional, and technological setups. For instance, we find that the higher firms' bargaining strength, the smaller both average growth rates and their variability. Furthermore, if firms are less responsive to market signals, the economy enjoys persistently higher average growth rates and persistently smaller fluctuations. Similarly, higher technological opportunities imply higher average growth rates but more volatile growth rate time-series. Volatility can be however weakened if one increases firms strength in wage bargaining.

\section{References}

Aoki, M. (2003), "A New Model of Output Fluctuation: Ultrametrics, Beveridge Curve and Okun's Law", Economics online papers, no. 234, UCLA.

Aoki, M. and H. Yoshikawa (2003), "A Simple Quantity Adjustment Model of Economic Fluctuations and Growth", in Cowan, R. and N. Jonard (eds.), Heterogeneous Agents, Interaction and Economic Performance. Berlin, Springer.

Ashenfelter, O. and D. Card (eds.) (1999), Handbook of Labor Economics. Volume 3. Elsevier Science, Amsterdam.

Ashenfelter, O. and R. Layard (eds.) (1986), Handbook of Labor Economics. Volume 2. Elsevier Science, Amsterdam.

Attfield, C. and B. Silverstone (1997), "Okun's coefficient: A comment", The Review of Economics and Statistics, 79: 326-329.

Blanchard, O. and P. Diamond (1989), "The Beveridge curve", Brooking Papers on Economic Activities, 1: 1-76.

Blanchard, O. and L. Katz (1997), "What We Know and Do Not Know about the Natural Rate of Unemployment", Journal of Economic Perspectives, 11: 57-72.

Blanchflower, D. and A. Oswald (1994), The Wage Curve. Cambridge, Massachussetts, The MIT Press.

Bleakley, H. and J. Fuhrer (1997), "Shifts in the Beveridge Curve, Job Matching, and Labor Market Dynamics", New England Economic Review, 2: 3-19.

Borsch-Supan, A. (1991), "Panel Data Analysis of the Beveridge Curve: Is There a Macroeconomic Relation between the Rate of Unemployment and Vacancy Rate?", Economica, 58: 279-297.

Burdett, K., S. Shi and R. Wright (2001), "Pricing and Matching with Frictions", Journal of Political Economy, 109: 1060-1085.

Cao, M. and S. Shi (2000), "Coordination, matching and wages", Canadian Journal of Economics, 33: 1009-1033.

Card, D. (1995), "The Wage Curve: A Review", Journal of Economic Literature, 33: 785-799.

Card, D. and D. Hyslop (1996), "Does Inflation Grease the Wheels of the Labor 
Market", Working paper 5538, NBER.

Dosi, G. and R. Nelson (1994), "An introduction to evolutionary theories in economics", Journal of Evolutionary Economics, 4: 153-172.

Dosi, G. and L. Orsenigo (1994), "Macrodynamics and microfoundations: an evolutionary perspective", in Granstrand, O. (ed.), The economics of technology. Amsterdam, North Holland.

Dosi, G. and S. Winter (2002), "Interpreting Economic Change: Evolution, Structures and Games", in Augier, M. and J. March (eds.), The Economics of Choice, Change, and Organizations. Cheltenham, Edward Elgar Publishers.

Epstein, J. and R. Axtell (1996), Growing Artificial Societies: Social Science from the Bottom-Up. Washington D.C., MIT Press.

Fagiolo, G., G. Dosi and R. Gabriele (2004), "Towards an Evolutionary Interpretation of Aggregate Labor Market Regularities", Working paper, LEM-WP 2004-02, Sant'Anna School of Advanced Studies, Laboratory of Economics and Management.

Flaschel, P., G. Kauermann and W. Semmler (2003), "Testing Wage and Price Phillips Curves for the United States", Unpublished manuscript, Bielefeld University, Faculty of Economics.

Forni, M. and M. Lippi (1997), Aggregation and the Microfoundations of Dynamic Macroeconomics. Oxford, Clarendon Press.

Hahn, F. and R. Solow (1997), A Critical Essay on Modern Macroeconomic Theory. Cambridge, MA, The MIT Press.

Julien, B., J. Kennes and I. King (2000), "Bidding for Labor", Review of Economic Dynamics, 3: 619-649.

Kirman, A. (1992), "Whom or what does the representative individual represent ?", Journal of Economic Perspectives, 6: 117-136.

Kirman, A. (1997), "The Economy as an Interactive System", in Arthur, W., S. Durlauf and D. Lane (eds.), The Economy as an Evolving Complex System II. Santa Fe Institute, Santa Fe and Reading, MA, Addison-Wesley.

Laffond, G. and J. Lesourne (2000), "The genesis of expectations and of sunspot equilibria", Journal of Evolutionary Economics, 2: 211-231.

Lagos, R. (2000), "An Alternative Approach to Search Frictions", Journal of Political Economy, 108: 851-872.

Lesourne, J. (1992), The Economics of Order and Disorder. Oxford, Clarendon Press.

Nickell, S., L. Nunziata, W. Ochell and G. Quintini (2001), "The Beveridge curve, Unemployment and wages in the OECD from 1960s to 1990s", Working paper no. 502, CEPR, London, U.K.

Okun, A. (1962), "Potential GDP: Its Measurement and Significance", Proceedings of the Busisness and Economics Statistics, pp. 98-103.

Okun, A. (1970), The political economy of prosperity. The Brookings Institution, Washington D.C.

Peters, M. (1991), "Ex ante price offers in matching games non-steady states", 
Econometrica, 59: 1425-1454.

Petrongolo, B. and C. Pissarides (2001), "Looking into the Black Box: A Survey on the Matching Function", Journal of Economic Literature, 39: 390-431.

Phelps, E. (1994), Structural Slumps. Cambridge, Harvard University Press.

Phelps, E. and S. Winter (1970), "Optimal Price Policy Under Atomistic Competition", in Phelps, E., G. Archibald and A. Alchian (eds.), Microeconomic Foundations of Employment and Inflation Theory. New York, Norton.

Pissarides, C. (2000), Equilibrium Unemployment Theory. Oxford, Blackwell.

Prachowny, M. (1993), "Okun's Law: Theoretical Foundations and Revised Estimates", The Review of Economics and Statistics, 75: 331-336.

Smith, T. and Y. Zenou (2003), "A Discrete-Time Stochastic Model of Job Matching", Economic Dynamics, 6: 54-79.

Solow, R. (1998), "What is Labour-Market Flexibility? What is it Good for?", Proceedings of the British Academy, 97: 189-211.

Tesfatsion, L. (1997), "How Economists Can Get ALife", in Arthur, W., S. Durlauf and D. Lane (eds.), The Economy as an Evolving Complex System II. Santa Fe Institute, Santa Fe and Reading, MA, Addison-Wesley.

Tesfatsion, L. (2001), "Structure, Behavior, and Market Power in an Evolutionary Labor Market with Adaptive Search", Journal of Economic Dynamics and Control, 25: 419-457.

Witt, U. (1985), "Coordination of Individual Economic Activities as an Evolving Process of Self-Organization", Economie appliquée, 37: 569-595. 